\title{
A novel mutation in PSEN1 (p.Arg41Ser) in an Argentinian woman with early onset Parkinsonism
}

\section{Autores}

Emilia M. Gatto, Galeno J. Rojas, Sergio I. Nemirovsky, Gustavo Da Prat, Gabriel Persi, Martin

Cesarini, Jose L. Etcheverry, Natalia Gonzalez Rojas, Virginia Parisi, Marta Cordoba.

\begin{abstract}
Palabras clave

Parkinsonism, Presenilin, Genetics, PSEN1
\end{abstract}

Mutations in presenilin-1 (PSEN1) account for the majority of cases of familial autosomal dominant early-onset Alzheimer's disease (AD) as well as in sporadic forms. Atypical presentations are reported including extrapyramidal signs. In the last years, a pleiotropic effect of some PSEN1 variants has been reported in Parkinson's disease (PD). 